\title{
YOĞUNLAŞTIRILMIŞ YÜRÜYÜŞ VE JOGGING PROGRAMININ YÜKSEK DANSITELI LIPOROTEIN (HDL) VE DÜŞÜK DANSITELI LIPOPROTEINLER (LDL) ÜZERINE OLAN ETKISI
}

\author{
Halil ÇOLAK ${ }^{1}$
}

\author{
Rasim KALE ${ }^{2}$
}

\section{ÖZET}

Yapılan bu çalışmanın amacı, yoğunlaştırılmış yürüyüş ve jogging programının koroner kalp hastalığı risk faktörlerinden olan yüksek dansiteli liporotein (HDL) ve düşük dansiteli lipoprotein (LDL) üzerine olan etkisini araştırmaktır. Çalışmaya, 66 denek ( 30 erkek ve 36 bayan) gönüllü olarak katılmışlardır. Denekler random metodu ile iki gruba ayrılarak, deney $(n=35)$ ve kontrol $(n=31)$ gruplarını oluşturdular.

Deney grubundaki katılımcılar hedef kalp atım sayısının (HKAS) \% 50- \% 85 arasında yüklenme şiddeti ile 10 hafta süre ile haftada 4 gün olmak üzere arttııılmış yürüyüş ve jogging programına tabi tutuldular. Tüm ölçümler antrenman programından bir gün önce ve sonra ön test ve son test olarak yapıldılar. İstatistiksel analizler, aritmetik ortalama (x), standart sapma ( SD ) ve "t test" olarak yapıldı.

Çalışmanın sonunda; ölçümlerde uygulanan aritmetik uygulamalar arası farka ait " $t$ testi” nde ölçümü yapılan parametrelerden ağırlık, BKI,DKAS, EKAS, TG, TC ve HDL-C erkek denek ve kontrol grupları arasındaki fark, istatistiki açıdan anlamlı bulunmuştur ( $p<$ $0.05)$, ESBP ve LDL-C değerleri matematiksel olarak anlamlı istatistiksel olarak ise anlamsız bulunmuştur. Bayan denek ve kontrol grupları karşılaştırıldığında ise fark, DKAS, EKAS, TG,TC, LDL-C ve HDL-C değerleri anlamlı bulunmuştur $(p<0.05)$ ancak ağılık ve BKI anlamlı bulunmamıştır.

Sonuçta; düzenli fiziksel aktivitede bulunan kişilerde HDL-C değeri artarken, LDL-C değerinde düşüş görülmüştür.

(LDL).

Anahtar Kelimeler : Yoğunlaştırılmış Yürüyüş ve Jogging; Yüksek Densiteli Lipoprotein (HDL); Düşük Densiteli Lipoprotein

\section{THE EFFECTS OF THE DENSELY WALKING AND COGGING PROGRAMS ON HIGH DENSITY LIPOPROTEIN(HDL-C) AND LOW DENSITY LIPOPROTEIN (LDL-C)}

\section{ABSTRACT}

The purpose of this studyt was to asses the effects of the densely walking and jogging programs on high densty lipoprotein (HDL-C) and low density lipoprotein (LDL-C). Sixty six person (30 male and 36 female) participated as subject of an expriment. Their age values were male $(x=46.3 \pm 5.7)$ and female $(x=44.5 \pm 2.7)$.

Subjects were divided into rwo groups with random method, as training and control groups. Subject of expriment group walket and run four times a week for ten weeks at their target heart rate that was bgetween $\% 50$ and $\% 85$. All measurements were taken a day before and after from the training program as pre and posttest.

The statical analysis of datas included mean ( $x$ ), standart deviation (SD), and paried $t-$ test.

The statistical analysis of these measurement showed that when the two groups of male were compared and the difference at weight, BMI, resting heart rate (RHR), resting systolic blood pressure (RSBP), restinng diastolic blood pressure ( RDBP), exercice heart rate (EHR), exercise diastolic blood ptessure (EDBP), TG, TC and HDL-C were found significandly $(p<0,05)$, but exercise systolic blood pressure (ESBP) and LDL-C were not significantly. The two groups of female were compared and difference at RHR, RSBP, RDBP, EHR, EDBP, TC, TG, LDL-C and HDL-C were found significantly $(p<0.05)$ but, weight losing, BMI and ESBP were not significantly.

In finally,both genders' HDL-C increased and LDL-C decreased wih regular physical activities.

Key Words : Walking and Jogging; High Density Lipoprotein (HDL); Low Density Lipoprotein (LDL).

\section{GIRIŞ VE AMAÇ}

Teknoloji gelişim günümüzde,insanoğluna bir takım kolaylıklar sağlamakla birlikte, onun bedensel

hareket kabiliyetine de sekte vuran bir takım dezavantajları da beraberinde getirmiştir. Sık araba kullanınmı, asansör gibi kolaylıklar onun bedensel olarak "hareketsizleşme" sini sağlamıştır. Özellikle Amerika Birleşik Devletleri, İngiltere gibi gelişmiş ülkelerde obesite, koroner kalp ve damar hastalıkları günümüzün en başta gelen sağlık sorunları olarak ortaya çıkmıştır. ABD'de koroner kalp hastalıklarına bağlı ölüm oranı kanser ve diğer hastalıkların oranından çok daha fazladır, Ülkemiz de de durum bundan pek farklı değildir. 1991 Yılından itibaren ülkemizde yapılan 8 yıllık TEKHARF çalışmasında; kentlerde yaşayanlarda KKH yakalanma oranı, kırsal kesim oranından \% 15 daha fazladır. Yine bu çalışmada ülke nüfusunun \% 2.3'ünün koroner kalp hastası olduğu belirtilmiştir (Onat, 2000).

\footnotetext{
KTÜ Giresun Meslek Yüksekokulu

${ }^{2}$ KTÜ Fatih Eğ. Fak. Beden Eğitimi ve Spor Bölümü
} 
Yüksek değerdeki LDL-C ve düşük değerdeki HDL-C, KKH risk faktörlerinin en önemlilerindendir (Pollock et al., 1978;Jung, 1988;Tuncel ve ark., 1997;AHA-Pub. 1999; Fox et al., 1999; Zorba, 1999; Tokgözoğlu, 2000). LDL-C, aterosklerozun gelişiminde en önemli rol oynayan lipid fraksiyonudur. Plasmada LDL-C' nin artması ile subendotelyal bölgede depolanmaya başlar. Bu da damar içinin daralması şeklinde karşımıza çıkar (Tokgözoğlu, 2000). HDL-C, KKH'da önleyici özelliğe sahiptir, Düzenli ve devamlı yapılan egzersiz HDL-C düzeyini arttırır.HDL-C arter duvarlarına yapışan yağları parçalayarak buradaki plaklaşmayı önler. HDL-C, damar duvarlarından parçaladığı LDL-C'yi reseptörleri ile karaciğere taşır (Bernstein et al., 2002)

Epidemiyolojik çalışmalar LDL-C nin \% 1 oranında azalmasının KKH gelişme riskini \% 2 azalttığını göstermiştir. Yine bu tür çalışmalarda infarktüs geçiren hastaların \% 25 'inde normal TC ve düşük HDL-C düzeyi tespit edilmiştir ( Visich et al., 1969; Enar, 1999, Solak ve ark., 2002).

Amerikan Ulusal Kalp-Akciğer ne Kan Enstitüsü (NHLBI)' ne göre LDL-C ve HDL-C düzeyleri aşağıdaki gibidir.

Tablo-1. Amerikan Kalp-Akciğer ve Kan Enstitüsü (NHLBI)' ne Göre LDL-C ve HDL-C Düzeyleri

\begin{tabular}{|l|ll|}
\hline LDL $-C$ & $130 \mathrm{mg} / \mathrm{dL}$ den az & arzu edilen \\
& $130-159 \mathrm{mg} / \mathrm{dL}$ & sınır-yüksek \\
& $160 \mathrm{mg} / \mathrm{dL}$ ve üstü & yüksek-risk \\
\hline HDL-C & $35 \mathrm{mg} / \mathrm{dL}$ ve altı & düşük \\
\hline
\end{tabular}

Kaynak : NHLBI pub., 1996,s.7

Ülkemizde yapılan TEKHARF çalışmasında 1997-98 döneminde 40-49 yaş arası erkek ve kadınlarda LDL-C ve HDL-C değerleri aşağıdaki gibi tespit edilmiştir (Tokgözoğlu,2000).

Tablo-2. TEKHARF 1997-98 Dönemi 40-49 Yaş Kadın ve Erkeklerde LDL-C veHDL-C Değerleri.

\begin{tabular}{|l|l|l|l|l|}
\hline Parametre & Kadın & $\mathrm{n}=$ & Erkek & $\mathrm{n}=$ \\
\hline LDL-C & $117.9 \pm 33.9 \mathrm{mg} / \mathrm{dL}$ & 242 & $116.6 \pm 33 \mathrm{mg} / \mathrm{dL}$ & 234 \\
\hline HDL-C & $44.4 \pm 13 \mathrm{mg} / \mathrm{dL}$ & 337 & $36.3 \pm 12 \mathrm{mg} / \mathrm{dL}$ & 319 \\
\hline
\end{tabular}

Kaynak : Tokgözoğlu,2000, TEKHARF,s:43.

Hareket eksikliği, birçok spor fizyoloğu ve bilim adamınca KKH'nın en önemli risk faktörlerinden biri olarak gösterilmiştir (Morehouse-Miller, 1973; Pollock et al,. 1978; Astrand- Rodahl, 1986; Akgün, 1993; Kale, 1993 ; İşleğen ve ark., 1994; Tuncel ve ark., 1997;AHA-Pub. 1999; Fox et al., 1999; Zorba, 1999;Erkan, 2000;Mahonanda et al.,2000;Onat ve ark.,2000; Tokgözoğlu, 2000; Twisk et al.,2000; Senti et al.,2001; Solak ve ark,.2002)

Sürekli yapılan orta şiddetteki ve submaksimal egzersizler LDL-C'de yaklaşık 5-10 mg/dL düşme ve HDL-C'de 2 mg/dL artış sağlar (Kale, 1993; Miller et al., 1997).

İnsülin resistansı artan serum trigliserid ve LDL-C , düşen HDL-C ile ilişkilidir. Fiziksel aktivite ve kilo kaybının insülin resistansı ve dislipoproteinemayı etkilediği de bilinmektedir (Halle et al., 1999 ; Scheen-Paqout ,2001). Egzersizle trigliseridin düşmesi, kas ve yağ dokuda artan lipoprotein lipase ile ilişkilidir. Lipoprotein lipase işleminde lipoproteinden zengin trigliseridin eriyip çözelmesi ile HDL fraksiyonlarında, özellikle HDL 2'de artış görülür (Thompson et al., 1990).

Çeşitli ülkelerde yapılan araştırmalarda, düzenli egzersiz yapan, serbest zaman aktivitelerinde bulunan ve tarım sektöründe çalışan iş̧̧iler üzerinde yapılan araştırmalarda düşük LDL-C ve yüksek HDL-C değerleri saptanmıştır (WoofMay.1998; Assorelli et al., 1998; Forest et al., 2001; Hu et al., 2001; Scheen- Paquot et al., 2001).

Yaman ve arkadaşları, kadınlarda \% 80'lik tempoda $3 \mathrm{gün} /$ hafta sıklıkla yapılan egzersizlerde lipid ve lipoproteinlerde olumlu değişimler saptamıştır (Yaman, 2002)

İşleğen ve arkadaşları, 8 aylık \%70-80 şiddetinde ve 2 gün/hafta sıklıkla uyguladığı bir çalışmada aşağıdaki sonuçları elde etmiştir (İşleğen ve ark., 1994).

Tablo-3. 8 Aylık Bir Program sonrası Görülen Değişiklikler.

\begin{tabular}{|l|l|l|l|}
\hline Değişken & Pretest & Posttest & \\
\hline HDL-C & $37.4 \pm 7.1 \mathrm{mg} / \mathrm{dL}$ & $38.4 \pm 5.7 \mathrm{mg} / \mathrm{dL}$ & anlamsız \\
\hline LDL-C & $166.3 \pm 39.7 \mathrm{mg} / \mathrm{dL}$ & $144.1 \pm 33.6 \mathrm{mg} / \mathrm{dL}$ & $\mathrm{P}<0.05$ \\
\hline
\end{tabular}

Kaynak:IŞLEĞEN ve ark.,1994,s:43-58

İtalya'da yapılan bir çalışmada, deneklere 8 haftalık bir egzersiz programı uygulanmış ve HDL-C'de \%14 artış, LDL-C'de ise \% 13 lük bir düşüş saptanmıştır (Sanguigni et al., 1994). 
Bütün bu çalışmalar göz önüne alındığında,düzenli ve devamlı yapılan egzersizlerin koroner kalp ve damar hastalıklarının önlenmesinde bir etken olduğu görülmektedir. araştırılmasıdır.

Bu çalışmanın amacı, 40-50 yaş grubundaki kişilerde egzersizin LDL_C ve HDL-C değerlerine olan etkisinin

\section{MATERYAL VE YÖNTEM}

$\mathrm{Bu}$ çalışmaya, koroner kalp hastalığı risk faktörlerine sahip ve çalışmaya kadar katılana kadar hiçbir fiziksel egzersiz programına katılmamış 40-49 yaş grubu toplam 66 denek katılmıştır.

Denekler, tesadüfi olarak, egzersiz $(n=35)$ ve kontrol $(n=31)$ olmak üzere iki gruba ayrılmışlardır. Denekler çalışma öncesi doktor kontrolünden geçirildi ve egzersiz programına katılmalarında bir sakınca olmadığı konusunda bilgilendirildiler. Egzersiz grubu 10 hafta süre ile haftada 4 gün olmak üzere $\% 50$ den başlayıp \%85‘e varan şiddette yürüyüş ve jogging programına tabi tutuldular. Deneklere ilk 7 hafta yürüyüş sonraki 3 haftada da jogging yaptırıldı. Tüm ölçümler, programın 1 gün önce ve sonrasında yapıldı. Çalışma alanı olarak Giresun Şehir stadyumu kullanıldı. Kan parametreleri Giresun Devlet Hastanesin'de analiz edildi.

Uygulanan egzersiz programında deneklerin hedef kalp atım sayıları (HKAS)'na göre tespit edildi. Bu metoda göre HKAS = ( 220- Yaş) X \% 50 Alt Sınır (220- Yaş) X \%85 Üst Sınır olarak belirlendi, Yine egzersizin frekansı da 4 gün/hafta olarak belirlenmiştir (Manness,1969;Zohmann, 1983; Powers, 1990; Thompson et al., 1990; AHA, 1999; Fox et al.,1999; Zorba, 1999; Erkan,2000; Yaman, 2002).

\section{Uygulanan Egzersiz Programı:}

Egzersiz programı iki bölümde uygulanmıştır. Birinci bölüm 2 hafta sürmüş olup bu bölümde deneklere çalışmanın amacı ve şekli anlatılarak, doğru yürüme şekli, uygun nefes alıp verme, ısınma ve soğuma hareketleri, kullanılacak kıyafetlerle ilgili bilgiler verilmiştir. İkinci bölüm 10 hafta süreli olup, bu bölümde ilk 7 hafta yürüyüş ve takip eden 3 hafta cogging uygulanmıştır. Uygulanan egzersiz programında deneklerin hedef kalp atım sayıları (HKAS)'na göre tespit edildi.

Bu metoda göre HKAS = ( 220- Yaş)X \% 50 Alt Sınır (220- Yaş) X \%85 Üst Sınır olarak belirlendi, Egzersizin yoğunlaştırılmış şiddeti 1-2 hafta \%50, 3. hafta: \%55, 4.hafta; \%60, 5. hafta; \%65, 6-7. Hafta; \%70, 8.hafta ; \%75, 9. hafta; $\% 80$ ve son hafta $\% 85$ olarak belirlendi.

Yine egzersizin frekansı da 4 gün/hafta olarak belirlenmiştir.

Egzersizin süresi ise; 15 dakika ısınma, 25-35 dakika ana bölüm ve 5 dakika soğuma devresi olarak belirlendi.

\section{Ölçüm Metodları:}

Ölçümler 3 ana başııta yapıldı;

- Antropometrik Ölçümler; Boy, ağırık, beden kitle indeksi(BKI)

- Dolaşım Parametreleri: Dinlenik ve egzersiz Kalp atım sayısı( DKAS-EKAS)

- $\quad$ Lipid Profili ; Trigliserid, total kolesterol, LDL-C, HDL-C

Boy ve Ağırlık Ölçümleri:Deneklerin boy ve ağırlıkları, çıplak ayak ve şort-penye ile ecza tipi baskül ile ölçüldü,

Beden Kitle İndeksi : Uluslar arası Sağlık Örgütü (WHO) tarafından kabul edilen aşağıdaki formülle hesaplandı.

$$
\text { BKi = Ağırlık I Boy }{ }^{2}
$$

Dinlenik Kalp Atım Sayısı (DKAS): Denekler 10 dakika sırt üstü yatar vaziyette dinlendikten sonra steteskop kullanılarak DKAS'sı tespit edildi. Test sabah 9.00'da yapıldı.

Egzersiz Kalp Atım Sayısı (EKAS) :Egzersizin ortasında yine steteskop kullanılarak yapıldı.

Total kolesterol (TC): Enzimatik end Point CHOD/PAP netodu ile yapılmış olup, normal değeri 0-200 mg /dL arasıdır,

Trigliserid (TG) :Enzimatik GPO/PAP metodu ile yapılmış olup, normal değerleri $50-20 \mathrm{mg} / \mathrm{dL}$ arasındadır.

LDL-C ve HDL-C :Çöktürmeli CHOD/PAP metodu ile yapılmış olup LDL-C normal değerleri 0-145 mg/dL ve HDL-C normal değerleri 0-55 mg/dL arasındadır. Ayrıca aşağıdaki Friedewald formülü kullanılmıştır.

$$
\text { LDL-C = TC- [ ( TG / 5) + HDL-C ] }
$$

İstatistik Analiz: Aritmetik ortalama (X). Standart sapma (SD) ve t- test uygulandı. 


\section{BULGULAR}

Egzersiz ve kontrol grubundaki deneklerin ön ve son test bulguları tablo- 4'te verilmiştir.

Tablo-4. Tüm Deneklere Ait Ön ve Son Test Değerleri

\begin{tabular}{|c|c|c|c|c|c|c|c|c|}
\hline \multirow[b]{2}{*}{ Değişken } & \multicolumn{2}{|c|}{ Denek Erkek n=15 } & \multicolumn{2}{|c|}{ Kontrol Erkek n=15 } & \multicolumn{2}{|c|}{ Denek Kadın n=20 } & \multicolumn{2}{|c|}{ Kontrol Kadın n=16 } \\
\hline & Öntest & Sontest & Öntest & Sontest & Öntest & Sontest & Öntest & Sontest \\
\hline AĞIRLIK & $81.5 \pm 7.5$ & $74.9 \pm 6.6$ & $83.4 \pm 4.4$ & $84.0 \pm 4.7$ & $78.5 \pm 8.7$ & $72.1 \pm 7.7$ & $75.9 \pm 5.9$ & $75.6 \pm 6.4$ \\
\hline BKI & $28.5 \pm 2.7$ & $26.1 \pm 2.2$ & $27.7 \pm 2.5$ & $28.6 \pm 3.1$ & $30.2 \pm 3.8$ & $27.7 \pm 3.3$ & $29.9 \pm 3.7$ & $29.8 \pm 3.9$ \\
\hline DKAH & $77.3 \pm 7.3$ & $72.6 \pm 6.7$ & $79.1 \pm 5.0$ & $79.1 \pm 5.4$ & $74.3 \pm 7.9$ & $70.4 \pm 6.0$ & $78.6 \pm 4.8$ & 5.1 \\
\hline EKAH & $148.1 \pm 9.8$ & $157.9 \pm 10.5$ & $139.7 \pm 9.1$ & $138.7 \pm 10.3$ & $142.5 \pm 6.3$ & $150.4 \pm 5.8$ & $137.8 \pm 8.5$ & $135.9 \pm 11.8$ \\
\hline TG & $251.7 \pm 93.0$ & $138.9 \pm 38.8$ & $198.6 \pm 73.4$ & $198.4 \pm 72.2$ & $209.6 \pm 70.7$ & $141.5 \pm 44.9$ & $181.3 \pm 60.6$ & $184.6 \pm 64.9$ \\
\hline TC & $266.8 \pm 27.4$ & $203.5 \pm 19.2$ & $223.9 \pm 35.6$ & $228.4 \pm 35.5$ & $239.7 \pm 44.8$ & $181.5 \pm 33.6$ & $238.9 \pm 29.9$ & $243.9 \pm 34.6$ \\
\hline LDL-C & $137.7 \pm 17.5$ & $120.3 \pm 15.6$ & $131.9 \pm 18.6$ & $129.3 \pm 24.2$ & $155.0 \pm 33.7$ & $112.4 \pm 30.5$ & $137.4 \pm 26.3$ & $135.4 \pm 27.8$ \\
\hline HDL-C & $40.9 \pm 6.3$ & $49.9 \pm 6.6$ & $40.7 \pm 6.0$ & $38.3 \pm 7.5$ & $42.7 \pm 6.8$ & $50.3 \pm 6.0$ & $41.5 \pm 7.0$ & $41.9 \pm 9.9$ \\
\hline
\end{tabular}

Tablo-5. Erkek Denek ve Kontrol Gruplarının Sontest Karşılaştırması

\begin{tabular}{|l|l|l|l|l|l|l|}
\hline Değişken & Erk.Denek & Erk.Kont & $\mathbf{t}$ & $\mathbf{t}$ tablo & Fark & \\
\hline Ağırlık & $74.9 \pm 6.6$ & $84.0 \pm 4.7$ & $-4.34^{*}$ & 2.05. & -9.1 & $\mathrm{p}<0.05$ \\
\hline BKI & $26.1 \pm 2.2$ & $28.6 \pm 3.1$ & $-2.55^{*}$ & 2.05 & -2.5 & $\mathrm{p}<0.05$ \\
\hline DKAS & $72.6 \pm 6.7$ & $79.1 \pm 5.4$ & $-2.93^{*}$ & 2.05 & -6.5 & $\mathrm{p}<0.05$ \\
\hline EKAS & $157.9 \pm 10.5$ & $138.7 \pm 10.3$ & $5.06^{*}$ & 2.05 & 19.2 & $\mathrm{p}<0.05$ \\
\hline TG & $138.9 \pm 38.8$ & $198.4 \pm 72.2$ & $-2.81^{*}$ & 2.05 & -59.5 & $\mathrm{p}<0.05$ \\
\hline TC & $203.5 \pm 19.2$ & $228.4 \pm 35.5$ & $-2.39^{*}$ & 2.05 & -24.9 & $\mathrm{p}<0.05$ \\
\hline LDL-C & $120.3 \pm 15.6$ & $129.3 \pm 24.2$ & -1.21 & 2.05 & -9 & \\
\hline HDL-C & $49.9 \pm 6.6$ & $38.3 \pm 7.5$ & $4.05^{*}$ & 2.05 & 11.6 & $\mathrm{p}<0.05$ \\
\hline
\end{tabular}

${ }^{*} p<0.05$

Tablo-5'de de görüldüğü üzere çalışmalara katılan erkek denek grubu ile katılmayan erkek kontrol grubunun son test karşılaştırmasında ağırlık (\% 9.1), beden kitle indeksi (2.5), dinlenik kalp atım sayısı ( \% 6.5 ), egzersiz kalp atım sayısı ( \% 19.2), trigliserid ( \% 59.5), total kolesterol (\% 24.9) veHDL-C (\% 11.6) değerlerindeki farklılık istatistiksel olarak anlamlı çıkmıştır $(p<0.05)$.

LDL-C değerleri matematiksel olarak farklı ( sırası ile \% 3.6 ve \% 9) çıkmasına rağmen bu farklılık istatistiksel olarak anlamlı çıkmamıştır.

Tablo-6. Bayan Denek ve Kontrol Gruplarının Sontest Karşılaştırması

\begin{tabular}{|l|l|l|l|l|l|l|}
\hline Değişken & Byn.Denek & Byn.Kont & $\mathbf{t}$ & $\mathbf{t}$ tablo & Fark & \\
\hline Ağırlık & $72.1 \pm 7.7$ & $75.6 \pm 6.4$ & -1.49 & 2.03 & -3.5 & \\
\hline BKI & $27.7 \pm 3.3$ & $29.8 \pm 3.9$ & -1.72 & 2.03 & -2.1 & \\
\hline DKAS & $70.4 \pm 6.0$ & $79.0 \pm 5.1$ & $-4.65^{*}$ & 2.03 & -8.6 & $\mathrm{p}<0.05$ \\
\hline DSBP & $122.0 \pm 10.2$ & $132.8 \pm 11.0$ & $-3.02^{*}$ & 2.03 & -10.8 & $\mathrm{p}<0.05$ \\
\hline DDBP & $79.5 \pm 6.3$ & $86.6 \pm 9.5$ & $-2.57^{*}$ & 2.03 & -7.1 & $\mathrm{p}<0.05$ \\
\hline EKAS & $150.4 \pm 5.8$ & $135.9 \pm 11.8$ & $4.51^{*}$ & 2.03 & 15.5 & $\mathrm{p}<0.05$ \\
\hline ESBP & $156.4 \pm 6.9$ & $157.2 \pm 7.5$ & -0.33 & 2.03 & -0.8 & \\
\hline EDBP & $94.2 \pm 6.6$ & $106.7 \pm 10.5$ & $-4.15^{*}$ & 2.03 & -12.5 & $\mathrm{p}<0.05$ \\
\hline TG & $141.5 \pm 44.9$ & $184.6 \pm 64.9$ & $-2.26^{*}$ & 2.03 & -43.1 & $\mathrm{p}<0.05$ \\
\hline TC & $181.5 \pm 33.6$ & $243.9 \pm 34.6$ & $-5.45^{*}$ & 2.03 & -62.4 & $\mathrm{p}<0.05$ \\
\hline LDL-C & $112.4 \pm 30.5$ & $135.4 \pm 27.8$ & $-2.36^{*}$ & 2.03 & -23 & $\mathrm{p}<0.05$ \\
\hline HDL-C & $50.3 \pm 6.0$ & $41.9 \pm 9.9$ & $2.98^{*}$ & 2.03 & 8.4 & $\mathrm{p}<0.05$ \\
\hline
\end{tabular}

${ }^{*} p<0.05$ 
Tablo-6'da da görüldüğü üzere çalışmalara katılan bayan denek grubu ile katılmayan bayan kontrol grubunun son test karşılaştırmasında dinlenik kalp atım sayısı ( \% 8.6), egzersiz kalp atım sayısı ( $\% 15.5)$, trigliserid ( \% 43.1), total kolesterol (\%62.4), LDL-C ( \%23) ve HDL-C (\% 8.4) değerlerindeki farklılık istatistiksel olarak anlamlı çıkmıştır ( $p<0.05)$.

Ağırık ve beden kitle indeksi değerleri matematiksel olarak farklı ( sırası ile \% 3.5ve \%2.1) çıkmasına rağmen bu farkılık istatistiksel olarak anlamlı çıkmamıştır.

\section{TARTIŞMA VE SONUÇ}

Bu çalışmada egzersizin LDL-C ve HDL-C üzerine olan etkileri araştırılmıştır.

Daha önceden yapılan çalışmalar, egzersizin LDL-C'nin düşmesinde önemli bir faktör olduğunu ispatlamaktadır ( GOLDBERG- ELLIOT, 1987; HESPEL et al., 1988; THOMPSON et al, 1990; KALE, 1993;KUSHIMA et al., 1994; C.SALDANA et al.,1995; EREN, 1997; ZIOGAS et al., 1997; KAYATEKIN ve ark.,1998; PIHL et al., 1998; WOOF-MAY, 1998; PRABHAKARAN et al., 1999; ASHTON et al.,2000; HALBERT et al., 2000; RIGLA et al., 2000; KIM et al.,2001; SCHEEN-PAQOUT, 2001; GUO et al., 2002). pub., 1996)

Amerikan Ulusal Kalp, Akciğer ve Kan Enstitüsü (NHLBI)'de 130 mg/dl'nin üstünü risk olarak belirtmiştir (NHLBI

BAYSAL ve arkadaşları LDL-C ortalama değerlerini 40-44 yaş grubu erkeklerde: 135, kadınlarda:130, 45-69 yaş grubu erkeklerde: 145, kadınlarda: $140 \mathrm{mg} / \mathrm{dl}$ olarak belirtmişlerdir . Bu değerlerin üstü ise risk olarak belirtilmiştir (BAYSAL ve ark., 1999).

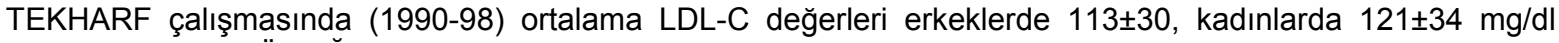
olarak saptanmıştır (TOKGÖZOĞLU, 2000).

Yapılan bir çalışmada normotensiflerde LDL-C değeri $3.35 \pm 0.23$, hipertensiflerde ise $3.38 \pm 0.21 \mathrm{mmol} / /$ olarak tespit edilmiştir (BILLGiN et al., 1994).

8 Haftalık bir egzersiz proğramı sonrası egzersiz yapanlarda LDL-C değeri 144.1 $\pm 33.6 \mathrm{mg} / \mathrm{dl}$, yapmayanlarda ise $166.3 \pm 39.7 \mathrm{mg} / \mathrm{dl}$ olarak belirlenmiştir (IŞLEĞEN ve ark., 1994). 1994).

İtalya'da yapılan 8 haftalık bir çalışma sonrası LDL-C'de \%13'lük bir düşüş saptanmıştır (SANGUIGNI et al.,

Türkiye'de yapılan bir çalışmada LDL-C değerleri İstanbul'da erkeklerde136 mg/dl, bayanlarda 100mg/dl, Adana'da erkeklerde ve kadınlarda $100 \mathrm{mg} / \mathrm{dl}$ olarak saptanmıştır (MAHLEY et al., 1995).

12 Haftalık bir egzersiz sonrası LDL-C değerinde 7.3'lük bir düşüş saptanmıştır (RUBINSTEIN et al., 1995).

İsviçre'de yapılan 3 aylık bir egzersiz proğramı sonrası LDL-c'de \%14'lük bir düşüş saptanmıştır (LEHMANN et al., 1997).

Amerika'da yapılan 1 yıl süreli bir egzersiz-diyet proğramı sonrası erkeklerde $20 \mathrm{mg} / \mathrm{dl}$, bayanlarda 14.5-22.2 mg/dl'lik bir düşüş saptanmıştır (STEFANICK et al., 1998).

1.5 Yıllık kardiyak bir rehabilitasyon proğramında erkeklerde 3.1, bayanlarda $3.4 \mathrm{mmol} / \mathrm{l}$ düşüş saptanmıştır( O'FARREL et al., 2000).

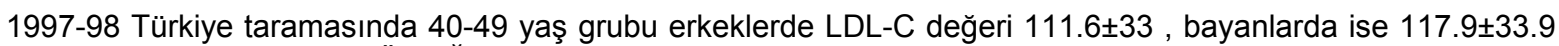
$\mathrm{mg} / \mathrm{dl}$ olarak tespit edilmiştir (TOKGÖZOĞLU, 2000).

$\mathrm{Bu}$ çalışmada elde edilen değerler ile bayan deneklerin değerleri paralellik arzetmekte olup erkek deneklerin değerleri 7-8 mg/dl kadar yüksek çıkmıştır. Burada bayan deneklerin egzersizin yanında diyet yaptıkları ve bu nedenle değerlerinin düşük olduğu düşünülebilir. Burada östrojen faktörü de rol oynamış olabilir.

Araştırmaya katılan grupların HDL- kolesterol ortalamaları; denek erkeklerde ön testte $40.9 \pm 6.3 \mathrm{mg} / \mathrm{dl}$ iken son testte $49.9 \pm 6.6 \mathrm{mg} / \mathrm{dl}$ bulunmuştur. Bu değerde \% 22.0 düşüş gözlenirken bu farklılık istatistiki olarak anlamlı bulunmuştur $(p<0.05)$. Kontrol erkeklerde bu değerin ortalaması son testte $38.3 \pm 7.5 \mathrm{mg} / \mathrm{dl}$ bulunmuştur. $10 \mathrm{Haftalık}$ ölçüm sonrası farklılık anlamlı bulunmamıştır. Bayan deneklerde öntestte HDL-C değeri $42.7 \pm 6.8$, sontestte $50.3 \pm 6.0$ $\mathrm{mg} / \mathrm{dl}$ dir. Bu grupta \% 17.8 değişim vardır. Bu fark istatistiksel olarak da anlamlı bulunmuştur $(p<0.05)$. Bayan kontrol grubunda HDL-C değeri son testte $41.9 \pm 9.9 \mathrm{mg} / \mathrm{dl}$ olarak bulunmuştur. 10 haftalık ölçüm sonrası bu gruptaki farkın anlamlı olmadığı saptanmıştır.

HDL-C kan damarlarının iç duvarındaki kolesterolün geri çekilmesinde ve serumdaki kolesterolün karaciğere taşınarak kan ve damar icerisinden uzaklaştırılmasında etkin rol oynaması nedeni ile koruyucu etki yapmaktadır (Sağlık ve Yaşam Dergisi, 1977)

Egzersiz, HDL-C değerlerinde artışa neden olmaktadır. Yapılan çalışmalar bu görüşü desteklemektedir ( NAKAMURA, 1981;KIENS et al., 1984; PELLETIER-BAKER, 1987; KALE, 1993; HELBERT et al., 1994; YOUNG et al., 1995; MARRUGAT et al., 1996; XI et al., 1996; MILLER et al.,1997; HSIEH et al., 1998; WOOF-MAY, 1998; ASSANELLI et al., 1999; BAUMAN-OWEN, 1999; KJAER, 2000; HU et al., 2001; SENTI et al., 2001; BERNSTEIN et al., 2002; GUO et al.,2002).

Lipoprotein lipase işleminde lipoproteinden zengin trigliseridin çözülmesi ile HDL fraksiyonlarında ( özellikle HDL 2'de) artış görülür (THOMPSON et al.,1990). al., 2002).

Yüksek yoğunlukta yapılan egzersizler kandaki ApoE4'ün etkileşimi nedeni ile HDL-C'yi artırır (BERNSTEIN et 
BAYSAL ve arkadaşları HDL-C normal değerlerini 40-44 yaş erkeklerde 50, bayanlarda $45 \mathrm{mg} / \mathrm{dl}$, 45-69 yaş grubu erkeklerde 50, bayanlarda $60 \mathrm{mg} / \mathrm{dl}$ olarak belirtmişlerdir (BAYSAL ve ark., 1999).

Birçok kaynak, HDL-C'nin 35 mg/dl'nin altına düşmesini KKH için risk faktörü saymaktadır (NHLBI pub., 1996; BAYSAL ve ark.,1999; ENAR, 1999; TOKGÖZOĞLU, 2000),

Belçika'da yapılan 16 haftalık bir egzersiz proğramı sonrası HDL-C fraksiyonlarında ortalama \%26 gibi büyük bir artış saptanmıştır (HESPEL et al., 1988).

İspanya'da askeri bir okulda yapılan egzersiz-diyet ağılıklı bir çalışmada (yaş X:19.9) $59.4 \pm 10.9$ mg/dl'lik HDLC değeri tespit edilmiştir. Bu grupta sigara kullanmayanlar ağırlıktadır (CASASNOVAS et al., 1992).

Ülkemizde yapılan bir çalışmada normotensiflerde HDL-C değeri $1.56 \pm 0.05 \mathrm{mmol} / \mathrm{l}$, hipertensiflerde ise $1.43 \pm 0.04 \mathrm{mmol} / \mathrm{l}$ olarak tespit edilmiştir (BILGIN e ark., 1994).

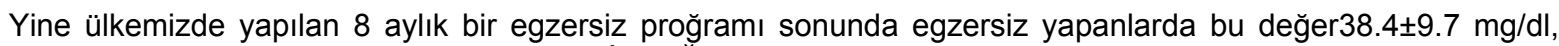
yapmayanlarda $37.4 \pm 7.1 \mathrm{mg} / \mathrm{dl}$ olarak saptanmıştır (IŞLEGEN ve ark., 1994).

PODL ve arkadaşları dayanıklılık antrenmanı yapan bayan atletlerde $62 \pm 14 \mathrm{mg} / \mathrm{dl}$ gibi yüksek birHDL-C değeri saptamıştır (PODL et al., 1994).

İtalya'da yapılan bir çalışmada 8 haftalık egzersiz proğramı sonrası HDL-C'de \%14'lük bir artış tespit edilmiştir (SANGUIGNI et al., 1994).

Diyabet hastalarına uygulanan 3 ylık bir egzersiz proğramı sonrasında HDL-C \% 23 oranında artış göstermiştir (LEHMANN et al., 1995).

Ülkemizde altı bölgede yapılan bir taramada erkeklerde $34-38 \mathrm{mg} / \mathrm{dl}$, bayanlarda $37-45 \mathrm{mg} / \mathrm{dl}$ HDL-C saptanmıştır (MAHLEY et al., 1995).

İsrail'de askerler üzerinde uygulanan 12 haftalık bir egzersiz proğramında öntestte $40.5 \pm 7.7$ mgdl, sontestte $52.8 \pm 8.7 \mathrm{mg} / \mathrm{dl}$ 'lik HDL-C değeri tespit edilmiştir (RUBISTEIN et al., 1995).

1997).

Üç aylık bir egzersiz sonrası yapılan ölçümlerde HDL-C'de \% 10'luk bir artış saptanmıştır (LEHMANN et al.,

3 Aylık bir başka egzersiz sonrası deneklerde \%8'lik bir HDL-C artışı saptanmıştır (BROCHU et al., 2000).

Ülkemizde yapılan TEKHARF (1990-98 yılları arasında) çalışmasında ortalama HDL-C değeri erkeklerde $37 \pm 12$

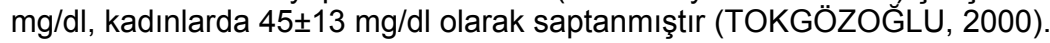

Sonuç olarak; bu çalışmada egzersiz grubundaki LDL-C düşüşü ve HDL-C artışı ile diğer çalışmalardaki değerler arasında benzerlik mevcuttur. Dolayısı ile düzenli ve devamlı yapılan egzersizler, LDL-C düzeyinde düşüşe, HDL-C düzeyinde de artışa neden olmaktadır,

\section{KAYNAKLAR}

1. AHA ;Exercise and your heart, American Heart Association Publ.Dallas :9-10, 1999

2. AKGÜN, N: : “Egzersiz Fizyolojisi”, GSGM, E.Ü.Basımevi,C: I, :41-68, c:2 ;158- 178,222,247, İzmir, 1993

3. ASHTON, W.D.,NANCHAHAL, K., WOOD, D.A: "Leisure- time physical activity and coronery risk factors in women", J Cardiovasc Risc 2000 Aug; 7 (4): 259-66.

4. ASSANELLI, D. BERSATTI, F. FERRARI ,R. BOLLANI, G. FERRARI, M. BALLORDINI, E. GUERRA, GP. PARRINELLO, G.: Effect of leisure time and working activity on principal risk factors and relative interaction in active middle- age men. Coron Artery Dis, 10 (1) : 1-7, 1999.

5. ASTRAND, PO. RODAHL,K.: "Textbook of work physiology, physiological basis of exercise", 3.Ed. McGraw-Hill Book Company N.York, :139-202,471-474, 1986

6. BAUMAN, A. OWEN,N.:" Habitual physical activity and cardiovascular risk factors", Sydney, Med J Aust Jan 7; 154 (1) : $22-8,1991$

7. BAYSAL, A ve ark : "Diyet El Kitabı", 3. Baskı, Hatipoğlu Yayınları, : 237-254, Ankara, 1999

8. BERNSTEIN, M.S.,COSTANZE, M.C., JAMES, R.W., MORRIS, M.A., CAMBEIN,F., RAOUX, S., MORABIA, A.: "Physical activity may modulate effect of ApoE genotype on lipid profile", Centre Medical Un, Geneva Switzerland, Arterioscler Tromb Vasc Biol Jan; 22 (1) : 133-40, 2002.

9. BILGIN,R. DONMA, O. GÜNDAY, V. SAĞLIKER, Y.: “Lipid profile and lipoproteins in essantiyel hypertension, "Tr.J. of Med. Sci. 20: 81-83, Ankara, 1994.

Blood Cholesterol, National Heart, Lung and Blood Institute Pub.Maryland:1-19,1996

10. BROUCH, M. POELMANN, ET. SAVAGE, P. FRAGNOLI- MUN, K. ROSS, S. ADES, PA: "Modest effects of exercise training alone on coronary risk factors and body composition in coronary patients", J Cardiopulm Rehabil May- Jun ; 20 (3) : $180-8,2000$.

11. CARDOSO SALDANA, G. C. Et al: "Lipid and lipoprotein levels in athletes in different sports disciplines", Arch Inst Cardiol Mex , May-Jun ; 65 (3) : 229-35, 1995.

12. CASASNOVAS, J.A. et al: "Tobacco, physical exercise and lipid profile”, Eur Heart J Apr ; 13 (4) : $440-5,1992$.

13. ENAR, R.: "Akut Myokard İnfarktüsü- komplikasyonlar 99”, Argos Yayınları:454, İstanbul,1999.

14. EREN, Zerrin.: "Hipertansiyon ve Egzersiz", Spor Araştırmaları Dergisi, MÜBSYO Yayınları,C.1, S:2:65-69,1997

15. ERKAN, Necmettin.:"Yaşam Boyu Spor”, Bağırgan Yayınevi , :8-10,47,63-76, Ankara, 2000.

16. FORREST,KY. BUNKER, CH. KRISTA, AM. UKOLI, FA. HUSTON, SL. MARKOVIC,N.: "Physical activity and cardiovascular risk factors in a developing population”, Med Sci Sports Exerc sep ; 33 (9) : 1598-604, Pittsburgh USA, 2001.

17. FOX, BOWERS, FOSS : “Beden eğitimi ve sporun fizyolojik temelleri, Çev:Mesut Cerit, Bağırgan Yayınları: $358-366$, Ankara, 1999. 
18. GOLDBERG, L. ELLIOT, DL.: "The effect of exercise on lipid metabolism in men and women", Portland, Sports Med Sept-Oct ; 4 (5) : 307-21, 1987.

19. GUO, X., MATOUSEK, M., SUNDH, V., STEEN, B.: "Motor performance in relation to age, anthropometric characteristics, and serum lipids in women", Goteborg Un. Sweeden, J Gerontol A Biol Sci Med Sci Jan; 57 (1) : M37-44, 2002.

20. HALBERT, JA. SILAGAY CA. FINUCANE, PM. WITHERS, RT. HAMDORF, PA.: "Physical activity and cardiovascular risk factors : effect of advice from an exercise specialist in Australian general practise", Med J Aust Jul 17 ; 173 (2) :84-7, 2000.

21. HELBERT, U., HERMAN, B, SHEA, S: "Moderate and vigorous leisure-time physical activity and cardiovascular disease risk factors in West Germany", 1984-1991. Int Epidemiol Apr;23(2):285-92, 1994.

22. HESPEL, P. LIJNEN,P. FAGARD,R. VAN HOOF,R. ROSSENEU, M. AMERY, A.: "Chances in plasma lipids and apoproteins associated with physical training in middle-aged sedentary men", Am Heart J Apr ; 115 (4) :786-92, 1988.

23. HSIEH, SD. YOSHINAGA, H. MUTO, T. SAKURAI, Y.: "Regular physical activitiy and coronary risk factors in Japanese men", Circulation Feb $24 ; 97$ (7):661-5, 1998.

24. HU, G. PEKKARINEN, H. HANNINEN, O. TIAN, H. GUO, Z.: "Relation between commuting leşsure time physical activity and serum lipids in a Chinese urban population”, Finland, Ann Hum Biol Jul-Aug ; 28 (4) : 412-21, 2001.

25. IŞLEĞEN, Ç. ve ark : "Düzenli yapılan egzersizlerin kardiak risk faktörlerine etkisi”,E.Ü.Spor Hek.Der. 29 (2):43-58, İzmir, 1994.

26. JUNG, K:" Klinik ve Uygulamada Ergometri”, çev:Kale,R. Alaş ofs. :14 ,İstanbul, 1988.

27. KALE, Rasim: "Sporda Dayanıklılık- Sağlık, Antrenman ve Biyofizyolojik Temeller,Alaş Ofs, İstanbul, 1993 "Kandaki total kolesterol tayini artık yetersiz" Sağlık ve Yaşam Dergisi, Veb Ofset, (12) : 51, İstanbul, 1977

28. KAYATEKIN, B.M. et al:"A comparison of the blood lipid profiles of professional sportspersons and controls", Indian J Physiol Pharmacol Oct;42(4) : 479-84, 1998.

29. KIENS, B, LITHELL H, VESSBY, B.: "Further increase in high density lipoprotein in trained males after enhanced training", Eur J Appl Physiol Occup Physiol; 52 (4):426-30, 1984

30. KIM, J. FLETCHER, G.F. LEE, J.Y: "Effect of exercise intensity and frequency on lipid levels in men coronary heart disease : Training level comparison trial", Am J. Cardiol Apr. 15;87 (8): 942-946.

31. KJAER, M. ANDERSEN, L.B. HANSEN, I.L.: "Physical activity- What minimal level is sufficent seen from health perspective ? ", Ugeskr Laeger Apr. 10 ; 162 (15):2164-9, 2000.

32. KUSHIMA,K. et al: "Effect of habitual physical activity on physical fitness and serum cholesterol in middle-aged male workers", Nippon Koshu Eisei Zasshi Apr, 41 (4) . 341-51, 1994

33. LEHMANN R, KAPLAN V, BINGISSER R, BLOCH KE, SPINAS GA.: "Impact of physical activity on cardiovascular risk factors in IDDM", Zurich, Diabetes Care Oct ; 20 (10): 1603-11,1997.

34. LEHMANN R, VOKAC, A. NIEDERMANN K, AGOSTI K, SPINAS GA.: "Loss of abdominal fat and improvement of cardiovascular risk profile by regular moderate exercise training in patients with NIDDM ( Non- Insulin- Dependent Diabetes Mellitus)", Zurich, Diabetologia Nov ; 38 (11) : 1313-9, 1995.

35. MAHLEY RW, PALAOĞLU KE, ATAK Z, DAWSON- PEPIN J, LANGLOIS AM, CHEUNG V, ONAT H, FULKS P, MAHLEY LL, VAKAR F, et al : "Turkish Heart Study: lipids, lipoproteins, and alipoproteins", San-Fransisco, J Lipid Res Apr ; 36 (4) : $839-59$, 1995.

36. MAHONONDA N, BHURIPANYO K, LEOWATTANA W, KANGKATAT C, CHOTINAIWATTARAKUL C, PANYARACHUN S, SUKRUNGREANG C :"Regular exercise and cardiovascular risk factors", J Med Assoc Thai Nov ;83 Suppl 2:S153-8, Bangkok, Thailand, 2000.

37. MANNES, B.:"Exercise Your Heart, Collier -Macmillan Ltd. London, : 29-30,1969

38. MARRUGAT, J. ELOSUA, R. COVAS, MI. MOLINA, L. RUBIES- PRAT, J.: "Amount and intensity of physical activity, physical fitness, and serum lipids in men, The Marathom Investigators", Am J Epidemiol Mar $15 ; 143$ (6) :562-9 (Erratum in -Aug 1; 144 (3) : 317, 1996.

39. MILLER, T.D., BALADY, G.J.,FLETCHER G.F.: "Exercise and its role in the prevention and rehabilitation of cardiovascular disease", Mayo Medical School,USA, Ann Behav Med Summer; 19 (3) : 220-9, 1997.

40. MOREHOUSE, L.E. MILLER, A.T.: Egzersiz Fizyolojisi, Çev:Akgün N. Ege Ü. Yayınları. :299-304, İzmir, 1973.

41. NAKAMURA, S.: "Influence of exercise and smoking on high- density lipoprotein cholesterol in university student"s, Thoku J Exp Med Dec ; 135 (4) : 443-4, 1981.

42. O'FARREL, P. MURRAY, J. HUSTON ,P. LEGRAND, C. ADAMO, K.: "Sex differences in cardiac rehabilitation", Can J Cardiol Mar ; 16 (3) : 319-25, 2000.

43. ONAT, Altan, SANSOY, Vedat, SOYDAN, İnan, TOKGÖZOĞLU, Lale, ADALET, Kamil:: "Tekharf"Türk Erişkinlerinde Kalp Sağlığı, Risk Profili ve Kalp Hastalığı "Onan Matb. :16-92, İstanbul,2000.

44. PELLETIER, DL., BAKER, PT.: "Physical activity and plasma total- and HDL- cholesterol levels in Western Samoan men", Am J Clin Nutr Oct; 46(4) :577-85, 1987.

45. PIHL, E. JURIMAE, T. KAASIK, T.:"Coronary heart disease risk factors in middle-aged former top-level athletes",Scand J Med Sci Sports Aug ; 8 (4) :229-35, 1998.

46. PODL, T.R. et al : "Lipoprotein lipase activity and plasma triglyceride clearence are in endurance-trained women", Metabolism Jul; 43 (7):808-13, 1994.

47. POLLOCK, M.L, WILMORE, J.H,FOX,S.M: Health and fitness through physical activity, J.Wiley\& Sons , Newyork :9-10, 1978

48. POWERS, Scott .K:" Exercise Physiology-Theory and Application to Fitness and Performance", 2.Ed. Human KineticsPub, Champign :329-361,1990

49. PRABHAKARAN, B. DOWLING, EA. BRANCH, JD. SWAIN, DP, LEUTHOLTZ, BC.: "Effect of resistance training on lipid profile and body fat percentage in premenopausal women", Br J Sports Med Jun ; 33 (3) : 190-5, 1999.

50. RABKIN, SW. CHEN, Y. LEITER, L. LIU, L. REEDER, BA.: Risk factor correlates of body mass index, Canadian Heart Health Surveys Research Group, CMAJ Jul 1; 157 Suppl 1:S26-31, 1997. 
51. RIGLA M, SANCHEZ- QUESADA JL, ORDONEZ- LLANOS J, PRAT T, CAIXAS A, JORBA O, SERRA JR, de LEIVA A, PEREZ A.: "Effect of physical exercise on lipoprotein ( a) and low- density lipoprotein modification in type 1 and type 2 diabetics patients", Metabolism May ; 49 (5) :640-7, 2000.

52. RUBINSTEIN, A. BURSTEIN, R. LUBIN, F. CHEPRIT, A. DANN, EJ. LEVTOV, O. GENTER, R.GUESTER, PA. DOLEV, E.: Lipoprotein profile changes during intense training of Israeli military recruits, Med Sci Sports Exerc, Apr; 27 (4);480-41995.

53. SANGUIGNI, V. et al: "Effect of physical activity on lipids and coagulation", Clinical trial, Cardiologia Jun;39 (6):425-39, 1994.

54. SCHEEN, AJ. PAQUOT, N.: "Beneficial effects of physical activitiy on cardiovascular risk factors", Rev Med Liege Apr; 56 (4) : 239 43, 2001.

55. SENTI, M. ELOSUA, R. TOMAS,M. SALA, J. MASIA, R. ORDOVAS, JM. SHEN, H. MARRUGAT, J.: "Physical activity modulates the combined effects of a common variant of the lipoprotein lipase gene and smoking on serum trigliseride levels and high- density lipoprotein cholesterol in men". Hum Genet Oct ; 109 (4) : 385-92, 2001.

56. SOLAK,H.GÖRMÜŞ, IS. SOLAK, T. GÖRMÜŞ, N.: "Spor ve Kalbimiz" ,Nobel Yayınları, s. 34-43, Ankara, 2002.

57. STEFANICK, M.L, MACKEY, S., SHEEHAN , M., ELLSWORTH, N., HASKELL, W.L., WOOD, P.D.: "Effect of diet end exercise in men and postmenopausal women with low levels of HDL cholesterol and high levels of LDL cholesterol", N Engl J Med Jul 2; 339 (1) :12-20, Stanford Un. California, USA, 1998.

58. THOMPSON, GR. CARLSON, LA. ILLINGWORTH, DR. STEIN, E. UTERMANN, G.: A Handbook of HYPERLIPIDAEMIA , Current Science Ltd.London, ;12-13, 168-172, 1990.

59. TOKGÖZOĞLU, Lale.: "Tekharf Çalışmasında "Türk Erişkenlerinde Lipid, Lipoprotein ve Alipoproteinler." Onan matb.:35-45, İstanbul, 2000.

60. TUNCEL, Fehmi, KOŞAR, Ş, Nazan, ÖMÜRLÜ, K.Yılmaz (Çev): “Temel Hayat Kurtarma, Sanem Matb., :19-24, Ankara, 1997.

61. TWISK, JW. KEMPER, HC. VAN MeECHELEN W.: "Tracking of activity and fitness and the relationship with cardiovascular disease risk factors", Med Sci sports Exerc Aug ; 32 (8) : 1455-61, 2000.

62. UĞRAŞ, Alper Faruk :"Elit düzeyde spor yaptıktan sonra yarışma sporunu bırakmış sporcularda koroner kalp hastalıkları risk profilinin araştırıması", GÜ. Sağlık Bil.Enst. Doktora Tezi, Ankara, 1999.

63. VISICH, PS, GOSS, FL. GORDON, PM, ROBERTSON, RJ. WARTY, V. DENYS, BG. METZ, KF:" Effect of exercise with varying energy expenditure on high- density lipoprotein-cholesterol", Eur J Appl Physiol Occup Physiol ; 72 (3) : 242-48, 1996.

64. WOOF-MAY, K. KEARNEY, EM. JONES, DW. DAVISON, RC. COLEMAN, D, BIRD, SR.: The effect of two- different 18 week walking programmes on aerobic fitness, selected blood lipids and factor XII a, J sports Sci Nov; 16 (8) :701-10, 1998.

65. YAMAN, Hakan : Kadın ve spor kavramına ilişkin güncel gelişmeler,Spor ve Tıp Der. Oc-Nis 10(1-2) :30, 2002.

66. YOUNG, DR. SHARP, DS. CURB, DJ.: Association among baseline physical activity and subsequent cardiovascular risk factors, Med Sci Sports Exerc Dec; 27 (12) :1646-54, 1995.

67. ZIOGAS, GG. THOMAS, TR. HARRIS, WS.:Exercise training, postprandial hypertriglyceridemia, and LDL subfraction distribution, Med Sci Spotrs Exerc Aug ; 29 (8) : 986-91, 1997.

68. ZOHMAN , L.R : "Exercise your way to fitness and heart health", American Heart Association Pub.:11-19, Dallas(Texas ,1983.

69. ZORBA, Erdal.: Herkes İçin Spor ve Fiziksel Uygunluk, GSGM y,:38-41, 60-66, 273, Ankara , 1999. 